\title{
COMUNIDADES REMANESCENTES DE QUILOMBOS: CONTRIBUIÇÃO AOS DOMÍNIOS FÍSICO, SOCIAL, PSICOLÓGICO E AMBIENTAL
}

\author{
QUILOMBO REMNANT COMMUNITIES: \\ CONTRIBUTIONS TO THE PHYSICAL, SOCIAL, \\ PSYCHOLOGICAL AND ENVIRONMENTAL DOMAINS
}

\section{COMUNIDADES REMANENTES DE QUILOMBOS: CONTRIBUCIONES PARA LOS DOMINIOS FÍSICO, SOCIAL, PSICOLÓGICO Y AMBIENTAL}

\author{
Milleidy Cezar Peixoto \\ Cláudia Cecília Blaszkowski de Jacobi ${ }^{2}$ \\ Larissa Rolim Borges-Paluch ${ }^{3}$
}

\begin{abstract}
Como citar este artigo: Peixoto MC, Jacobi CCB, Borges-Paluch LR. Comunidades remanescentes de quilombos: contribuição aos domínios físico, social, psicológico e ambiental. Rev baiana enferm. 2020;34:e34552.

Objetivo: comparar a qualidade de vida de pessoas que vivem em comunidades remanescentes de quilombos em municípios baianos. Método: pesquisa de caráter descritivo e abordagem quantitativa aplicada a moradores de duas comunidades remanescentes de quilombo, localizadas no estado da Bahia. Para a coleta de dados de qualidade de vida foi aplicado o formulário WHOQOL-Bref. Os dados foram explorados quanto às similaridades e diferenças entre as variáveis estudadas em cada comunidade. Resultados: com relação ao domínio físico, há baixo escore nas variáveis dor e desconforto, que causam falta de energia para as atividades cotidianas e fadiga. Também houve baixo escore em espiritualidade no domínio psicológico nas duas comunidades. No domínio meio ambiente, a variável recurso financeiro obteve escores baixos, mas o domínio relações sociais apresentou resultados satisfatórios. Conclusão: na análise geral dos escores das facetas, percebe-se que as comunidades remanescentes de quilombos possuem perfis semelhantes.
\end{abstract}

Descritores: Qualidade de Vida. Grupos Étnicos. Populações Vulneráveis.

Objetive: to compare life quality of people living in quilombo remnant communities in municipalities of Bahia. Method: descriptive and quantitative research involving inhabitants of two quilombo communities in the state of Bahia. Life quality data were collected by means of the WHOQOL-Bref questionnaire. Data were analyzed in terms of similarities and differences between the chosen variables in each community. Results: with regard to the physical domain pain and discomfort, which cause lack of energy for routine activities and fatigue, had a low score. In the psychological domain the score for spirituality was also low in both communities. In the environmental domain the

\footnotetext{
Enfermeira. Mestre em Desenvolvimento Regional e Meio Ambiente. Docente da Faculdade Maria Milza. Governador Mangabeira, Bahia, Brasil. https://orcid. org/0000-0002-8404-3379.

Bióloga. Doutora em Ciências. Docente do Programa de Mestrado Profissional Desenvolvimento Regional e Meio Ambiente da Faculdade Maria Milza. Governador Mangabeira, Bahia, Brasil. https://orcid.org/0000-0003-1907-7/90.

Bióloga. Doutora em Ciências Biológicas. Docente do Mestrado em Desenvolvimento Regional e Meio Ambiente e do Mestrado em Biotecnologia da Faculdade Maria Milza. Governador Mangabeira, Bahia, Brasil. larissapaluch@gmail.com. http://orcid.org/0000-0002-1810-0902.
} 
variable financial resources obtained low scores, but in the social relations domain satisfactory results were obtained. Conclusion: the general analysis of the facets scores shows that both quilombo communities have similar profiles.

Descriptors: Life Quality. Ethnic Groups. Vulnerable Populations.

Objetivo: comparar la calidad de vida de los residentes en comunidades remanentes de los quilombos en municipios de Babía. Método: investigación descriptiva y cuantitativa realizada con residentes de dos comunidades remanentes de los quilombos en el estado de Bahía. Los datos sobre calidad de vida se recolectaron a través del cuestionario WHOQOL-Bref. Esos datos fueron analizados en términos de similitudes y diferencias entre las variables elegidas en cada comunidad. Resultados: en lo que se refiere al dominio físico dolor y malestar, que causan falta de energía para realizar las tareas cotidianas y fatiga, obtuvo bajo puntaje. En el dominio psicológico el puntaje para espiritualidad también fue bajo en ambas comunidades. En el dominio ambiental la variable recursos financieros recibió puntaje bajo. Sin embargo, en el dominio relaciones sociales los resultados fueron satisfactorios. Conclusión: el análisis general de los puntajes de las facetas muestra que ambas comunidades tienen perfiles similares.

Descriptores: Calidad de Vida. Grupos Étnicos. Poblaciones Vulnerables.

\section{Introdução}

A formação dos mocambos ou quilombos no Brasil ocorreu devido às condições reais e objetivas de tratamento aos negros no período da escravidão, que os levou a desenvolverem estratégias de repúdio a esse sistema. Os habitantes desses territórios recebem o nome de quilombolas e são a tradução de lutas constituídas no seio do escravismo no Brasil ${ }^{(1)}$.

No país, há comunidades negras, urbanas e rurais, atualmente reconhecidas juridicamente como Território Remanescente de Comunidade Quilombola, que se localizam na área ocupada pelos antigos quilombos. Essas comunidades são formadas por grupos étnico-raciais negros dotados de relações territoriais específicas e caracterizadas pela resistência à opressão histórica sofrida. O reconhecimento desses territórios é uma concretização das conquistas da comunidade afrodescendente no país ${ }^{(2)}$.

Vale ressaltar que o Brasil é o país onde habita o maior número de negros fora do continente africano. Logo, é inaceitável desconhecer ou ignorar as necessidades dessa população, no que tange ao acesso à educação, mercado de trabalho, serviços de saúde e políticas públicas que melhorem a Qualidade de Vida (QV) desses indivíduos ${ }^{(3)}$.

Nas últimas três décadas, a QV tem gradualmente se tornado importante ferramenta para a análise da assistência à saúde. Nesse período houve aprimoramento e sofisticação na sua metodologia de apreciação, sendo focada em avaliações subjetivas que medem a percepção de cada indivíduo. É importante destacar que a QV engloba diversos aspectos importantes na saúde humana, não sendo relacionada exclusivamente ao acesso a serviços médico-assistenciais de qualidade ${ }^{(4)}$.

Diante do cenário de dificuldade de acesso aos bens coletivos pelos moradores de comunidades remanescentes de quilombos (CRQ), surge o interesse em aprofundar o conhecimento acerca dos aspectos gerais e de saúde, assim como os fatores intrínsecos e extrínsecos que impactam a QV destas populações. Diante do exposto, o estudo traz como questão de investigação: como se encontra a QV de pessoas que vivem em comunidades quilombolas de municípios baianos? Este questionamento é relevante, porque a QV e a saúde dessas populações é uma temática primordial para a efetiva implantação de políticas públicas adequadas às necessidades desse grupo.

Nesse contexto, a pesquisa teve como objetivo geral comparar a qualidade de vida de pessoas que vivem em CRQ em dois municípios baianos.

\section{Método}

A pesquisa teve natureza descritiva e abordagem quantitativa. O local de estudo limitou-se a duas CRQ localizadas na Bahia, doravante 
denominadas de CRQ1 e CRQ2. Na CRQ1, as pessoas são adscritas e acompanhadas em unidade sediada em bairro na zona urbana do município, distante cerca de $5 \mathrm{~km}$ da comunidade, e é assistida diariamente pela Agente Comunitária de Saúde (ACS). A CRQ2 é assistida por uma unidade de saúde satélite (vinculada a um Estabelecimento de Saúde de Atenção Básica, utilizada como base da equipe, visando à realização da atenção de forma descentralizada), localizada no próprio quilombo, que facilita o acesso desses moradores às consultas quinzenais médicas $\mathrm{e}$ de enfermagem.

A quantidade de participantes envolvidos na pesquisa foi definida por meio de análise estatística para a realização de uma amostragem aleatória estratificada, com o intuito de melhorar a precisão nas estimativas da média da população. Na CRQ1 há 365 pessoas residentes; destas, 251 são maiores de 18 anos. Já na CRQ2, há um total de 649 moradores, dos quais 472 são adultos.

O cálculo amostral considerou correção para a população finita, intervalo de confiança de $95 \%$, erro amostral de 5 pontos percentuais, sendo determinada uma amostra de 160 indivíduos. Os critérios de inclusão foram ser usuário da Unidade de Básica de Saúde (UBS) adstrita da CRQ, residir na comunidade há mais de um ano, e ter idade igual ou superior a 18 anos. Os critérios de exclusão foram os que se recusaram a participar da pesquisa, os ausentes da comunidade durante o período de realização da coleta de dados, e os que não foram encontrados na residência após 3 tentativas consecutivas. A amostra foi constituída por 143 pessoas, sendo 54 da CRQ1 e 89 da CRQ2; houve exclusão de 7 moradores que se recusaram a participar do estudo e 10 indivíduos que não foram encontrados após 3 visitas.

O período da coleta de dados foi de setembro a novembro de 2018. As entrevistas com os indivíduos para a coleta de dados foram realizadas em visitas às residências, juntamente com as ACS, em ambas as comunidades. Na CRQ2 também foram realizadas entrevistas na unidade satélite nos dias de atendimento.
Foi aplicado questionário com questões sociodemográficas e de saúde. Para avaliação da QV utilizou-se o questionário validado WHOQOL-bref, composto por 26 questões: 2 gerais de qualidade de vida e 24 representando cada uma das facetas que compõem o instrumento. A primeira questão diz respeito à qualidade de vida comum; a segunda, à satisfação com a própria saúde. As demais questões, em Escala Likert, estão divididas em quatro domínios: capacidade física, psicológica, relações sociais e ambientais.

As facetas, na escala, são analisadas de acordo com a seguinte classificação: "necessita melhorar" quando o escore for de 1 a 2,9; "regular" quando o escore for de 3 a 3,9; "boa" com escore de 4 a 4,9; e "muito boa" quando for um escore igual a 5. O escore final da QV é obtido pela soma das respostas dos participantes, e quanto maior a pontuação, melhor a percepção da QV, com exceção dos itens 3, 4 e 26, que possuem escore inverso.

Os dados foram analisados mediante estatística descritiva, utilizando-se o aplicativo Statistical Package for the Social Science (SPSS), que calcula a média aritmética, a mediana (Md) e o desvio padrão (DP) das respostas de todos os participantes.

Para verificar a consistência interna do instrumento de avaliação de QV na amostra estudada, calculou-se o Coeficiente Alfa de Cronbach. Esse coeficiente estima a confiabilidade (consistência interna) de um questionário aplicado em pesquisa, dando-lhe maior relevância e robustez. O valor mínimo aceitável para confirmar a confiabilidade das respostas é 0,70; abaixo desse valor a consistência interna da escala utilizada é considerada comprometida. O nível de significância adotado foi de $5 \%(\mathrm{p}<0,05)$ e o nível de confiança estatística foi de $95 \%$.

O estudo foi aprovado pelo Comitê de Ética em Pesquisa (CEP), sob o Parecer n. 2.586.014 e CAAE 86986618.8.0000.5025, e atendeu às normas éticas em pesquisa com seres humanos e de interesse estratégico para o Sistema Único de Saúde (SUS), preconizadas nas Resoluções $466 / 12^{(5)}$ e $580 / 18^{(6)}$. 


\section{Resultados}

Avaliando-se a faixa etária dos participantes da pesquisa verificou-se que a idade variou entre 18 anos e mais de 60 anos. A faixa etária predominante na CRQ1 foi de 25,9\% tanto para a faixa de 21 a 30 anos quanto para a de 31 a 40 anos. Na CRQ2, a faixa etária predominante também foi de 31 a 40 anos (25,8\%), seguida de indivíduos com mais de 60 anos (21,3\%). Em relação ao sexo, foi possível observar prevalência do sexo feminino nas duas comunidades $(66,7 \%$ na CRQ1 e 72\% CRQ2).

A maioria dos participantes das duas CRQ $(67,1 \%)$ afirmou seguir a religião católica, e na CRQ1, 27,8\% disseram ser protestantes. Alguns entrevistados, em ambas as comunidades, sinalizaram que seguem o catolicismo e o candomblé simultaneamente. No que se refere ao estado civil, a maioria era solteiro(a) (CRQ1 44\% e CRQ2 32,6\%), seguido de casados(as) (24,1\% e 30,3\% para CRQ 1 e 2, respectivamente).

Quanto ao grau de instrução dos participantes, foi possível verificar elevada porcentagem de moradores com nível médio completo (27,8 e 22,5\%, respectivamente). Entretanto, 9,3\% são apenas alfabetizados (somente assinam seu próprio nome) e 16,7\% são analfabetos na CRQ1, enquanto que na CRQ2, os valores são de 28,1\% e 5,6\%, respectivamente.

\section{Avaliação da qualidade de vida geral}

O alfa de Cronbach na CRQ1 obteve valores significativos $(0,72)$, indicando boa consistência interna nos domínios (Tabela 1 ). Em relação à CRQ2, o valor dos aspectos gerais foi 0,64, mostrando razoável consistência interna nos domínios (Tabela 2). O escore geral ficou muito próximo a 0,7 , indicando boa consistência (Tabela 3).

Tabela 1 - Consistência do Alfa de Cronbach por domínio na Comunidade Remanescente de Quilombo 1. Bahia, Brasil - 2018

\begin{tabular}{lcccc}
\hline Alfa de Cronbach & Escore Médio & Alpha de Cronbach & Escore WHOQOL \\
\hline Físico & 3,571 & 0,354 & 0,422 \\
Psicológico & 3,588 & 0,475 & 0,476 \\
Relações Sociais & 4,206 & 0,415 & 0,464 \\
Meio Ambiente & 3,336 & 0,536 & 0,511 \\
Geral & 3,576 & 0,720 & 0,732 \\
\hline
\end{tabular}

Fonte: Elaboração própria.

Tabela 2 - Consistência do Alfa de Cronbach por domínio na Comunidade Remanescente de Quilombo 2. Bahia, Brasil - 2018

\begin{tabular}{l|c|c|c}
\hline Alfa de Cronbach & Escore Médio & Alpha de Cronbach & Escore WHOQOL \\
\hline Físico & 3,516 & 0,405 & 0,476 \\
Psicológico & 3,568 & 0,468 & 0,443 \\
Relações Sociais & 3,691 & 0,312 & 0,314 \\
Meio Ambiente & 3,081 & 0,331 & 0,328 \\
Geral & 3,415 & 0,642 & 0,670 \\
\hline
\end{tabular}

Fonte: Elaboração própria.

Tabela 3 - Consistência do Alfa de Cronbach nas Comunidades Remanescentes de Quilombos 1 e 2. Bahia, Brasil - 2018

(continua)

\begin{tabular}{l|c|c|c}
\hline Alfa de Cronbach & Escore Médio & Alpha de Cronbach & Escore WHOQOL \\
\hline Físico & 3,550 & 0,374 & 0,440 \\
Psicológico & 3,580 & 0,458 & 0,447
\end{tabular}


Tabela 3 - Consistência do Alfa de Cronbach nas Comunidades Remanescentes de Quilombos 1 e 2. Bahia, Brasil - 2018 (conclusão)

\begin{tabular}{lcccc}
\hline Alfa de Cronbach & Escore Médio & Alpha de Cronbach & Escore WHOQOL \\
\hline Relações Sociais & 4,012 & 0,415 & 0,456 \\
Meio Ambiente & 3,240 & 0,486 & 0,471 \\
Geral & 3,515 & 0,698 & 0,713 \\
\hline
\end{tabular}

Fonte: Elaboração própria.

\section{Qualidade de vida}

Na Tabela 4 pode-se observar que a mediana obtida na faceta de QV geral (Como você avalia sua qualidade de vida?) na CRQ1 foi de 5,00 (muito bom), sendo esse o valor máximo. Na
CRQ2, a mediana foi 4,0 (bom). Comparando a mediana de ambas as comunidades, obteve-se 4,00 e, analisando a média das comunidades, pode-se perceber que, no geral, as respostas foram 3,87, um valor próximo de nem bom nem ruim.

Tabela 4 - Qualidade de vida geral, mediana, e desvio padrão das comunidades remanescentes de quilombo. Bahia, Brasil - 2018

\begin{tabular}{l|l|c|c|c|c|c|c|c|c}
\hline \multirow{2}{*}{ Questão } & \multirow{4}{*}{ Qualidade de vida geral } & \multicolumn{3}{c|}{ CRQ1 } & \multicolumn{3}{c|}{ CRQ2 } & \multicolumn{3}{c}{ Geral } \\
\cline { 3 - 10 } & & Média & MD & DP & Média & MD & DP & Média & MD \\
\hline 1 & $\begin{array}{l}\text { Qualidade de Vida de modo } \\
\text { geral }\end{array}$ & 4,0 & 5,00 & 1,16 & 3,78 & 4,00 & 0,91 & 3,87 & 4,00 \\
2 & $\begin{array}{l}\text { Satisfação com a própria } \\
\text { saúde }\end{array}$ & 3,7 & 5,00 & 1,47 & 3,69 & 3,00 & 1,38 & 3,70 & 3,00 \\
\hline
\end{tabular}

Fonte: Elaboração própria.

Legenda: $\mathrm{CRQ}=$ comunidade remanescente de quilombo; $\mathrm{MD}=$ mediana; $\mathrm{DP}=$ desvio padrão.

Analisando a QV geral da Tabela 4, relacionada à "satisfação com a própria saúde", a mediana da CRQ1 foi 5,0 enquanto a CRQ2 foi de 3,0. No geral, os indivíduos expressaram que a satisfação com a saúde não está boa nem ruim $(3,70)$. Esses resultados demonstram que os participantes encontram-se na classificação intermediária, pois consideram sua QV, de modo geral, "nem ruim nem boa"; o mesmo ocorrendo com a satisfação com a saúde.

Nos dados da Tabela 5, referente à QV relacionada ao Domínio Físico, é possível observar que, em ambas as CRQ, as facetas "dor e desconforto", e "energia e fadiga", obtiveram a mediana 1,0 (muito ruim) e 2,0 (ruim). Ao verificar os resultados em conjunto, observa-se que as médias (2,05 a 2,12) indicam que, no geral, as pessoas sofrem com alguma dor e desconforto e se sentem fatigadas e sem energia suficiente. Também pode se perceber que as facetas "sono e repouso", "dependência de medicações e tratamento", e "capacidade de trabalho" obtiveram escore médio de 3,82 a 3,98, o que significa dizer que os participantes não consideram essas facetas nem boas nem ruins.

Entretanto, quando é feita uma análise separada das comunidades, observa-se que na CRQ1 o escore "sono e repouso" e "mobilidade" obtiveram escore muito bom $(\mathrm{Md}=5,00)$, e na $\mathrm{CRQ} 2$, o escore para "mobilidade" e "atividades da vida cotidiana" foi de 5,00 (muito satisfeito).

Diante do exposto, percebe-se que no domínio físico $(\mathrm{Md}=3,67)$, no geral, as pessoas não estão satisfeitas ou insatisfeitas no que se refere às facetas pesquisadas. 
Tabela 5 - Qualidade de vida, mediana e desvio padrão referente ao domínio físico das comunidades remanescentes de quilombo. Bahia, Brasil - 2018

\begin{tabular}{|c|c|c|c|c|c|c|c|c|c|}
\hline \multirow{2}{*}{ Questão } & \multirow{2}{*}{ Facetas } & \multicolumn{3}{|c|}{$\begin{array}{c}\text { Comunidade Remanescente } \\
\text { Quilombo } 1\end{array}$} & \multicolumn{3}{|c|}{$\begin{array}{c}\text { Comunidade Remanescente } \\
\text { Quilombo } 2\end{array}$} & \multicolumn{2}{|c|}{ Geral } \\
\hline & & Média & MD & DP & Média & MD & DP & Média & MD \\
\hline 3 & $\begin{array}{l}\text { Dor e } \\
\text { desconforto }\end{array}$ & 1,9 & 1,00 & 1,31 & 2,26 & 2,00 & 1,18 & 2,12 & 2,00 \\
\hline 4 & Energia e fadiga & 2,2 & 1,00 & 1,51 & 1,98 & 1,00 & 1,28 & 2,05 & 1,00 \\
\hline 10 & Sono e repouso & 4,0 & 5,00 & 1,32 & 3,98 & 4,00 & 1,21 & 3,98 & 5,00 \\
\hline 15 & Mobilidade & 4,4 & 5,00 & 1,11 & 4,51 & 5,00 & 0,76 & 4,48 & 5,00 \\
\hline 16 & $\begin{array}{l}\text { Atividades de } \\
\text { vida cotidiana }\end{array}$ & 4,0 & 4,50 & 1,23 & 4,18 & 5,00 & 1,13 & 4,10 & 5,00 \\
\hline 17 & Dep Med e Trat* & 3,8 & 4,00 & 1,16 & 3,84 & 4,00 & 1,21 & 3,82 & 4,00 \\
\hline \multirow[t]{3}{*}{18} & $\begin{array}{l}\text { Capacidade de } \\
\text { trabalho }\end{array}$ & 3,7 & 4,00 & 1,31 & 3,93 & 4,00 & 1,19 & 3,84 & 4,00 \\
\hline & Escore Médio & & 3,52 & & & 3,57 & & & 3,55 \\
\hline & Escore Mediano & & 3,83 & & & 3,56 & & & 3,67 \\
\hline
\end{tabular}

Fonte: Elaboração própria.

Legenda: $\mathrm{MD}=$ mediana; $\mathrm{DP}=$ desvio padrão; ${ }^{\mathrm{D}}$ ep Med e Trat= dependência de medicação e tratamentos.

$\mathrm{Na}$ Tabela 6, referente à QV relacionada ao Domínio Psicológico, observa-se que em relação às facetas de "sentimentos positivos" e "pensar, aprender, memória e aparência" a mediana variou de bom a muito bom (4,0 a 5,0). Quanto à satisfação com a imagem corporal, na CRQ2, a mediana encontrada foi 5,0 (muito satisfeito) e na CRQ1 4,5. No geral, o escore 5,0 indica que a maioria dos entrevistados está muito satisfeito com a sua imagem e aparência corporal.
Em relação à autoestima e sentimentos negativos, os escores encontrados foram bons em ambas as CRQ $(\mathrm{Md}=4,0)$.

Diante dos resultados no domínio psicológico, observa-se que a mediana geral é positiva $(4,01)$. Entretanto, a faceta de "espiritualidade, religião e crenças pessoais" apresentou escore inferior aos demais, e a maioria dos entrevistados relatou estar muito insatisfeito $(1,0)$ com sua fé.

Tabela 6 - Qualidade de vida, mediana e desvio padrão referente ao domínio psicológico das comunidades remanescentes de quilombo. Bahia, Brasil - 2018

\begin{tabular}{|c|c|c|c|c|c|c|c|c|c|}
\hline \multirow{2}{*}{ Questão } & \multirow{2}{*}{$\begin{array}{l}\text { Facetas do Domínio } \\
\text { Psicológico }\end{array}$} & \multicolumn{3}{|c|}{ CRQ1 } & \multicolumn{3}{|c|}{ CRQ2 } & \multicolumn{2}{|c|}{ Geral } \\
\hline & & Média & MD & DP & Média & MD & $\mathbf{D P}$ & Média & MD \\
\hline 5 & Sentimentos positivos & 4,04 & 5,00 & 1,16 & 3,65 & 4,00 & 1,01 & 3,80 & 4,00 \\
\hline 6 & $\begin{array}{l}\text { Pensar, aprender, } \\
\text { memória e aparência }\end{array}$ & 3,72 & 5,00 & 1,47 & 4,42 & 5,00 & 0,72 & 4,41 & 5,00 \\
\hline 7 & Autoestima & 1,89 & 3,00 & 1,31 & 4,00 & 4,00 & 1,09 & 3,78 & 4,00 \\
\hline 11 & $\begin{array}{l}\text { Imagem corporal e } \\
\text { aparência }\end{array}$ & 2,17 & 4,50 & 1,51 & 3,98 & 5,00 & 1,25 & 4,01 & 5,00 \\
\hline 19 & Sentimentos negativos & 3,98 & 4,00 & 1,32 & 4,15 & 4,00 & 1,05 & 4,13 & 4,00 \\
\hline \multirow[t]{3}{*}{26} & $\begin{array}{l}\text { Espiritualidade/ religião/ } \\
\text { crenças pessoais }\end{array}$ & 4,43 & 1,00 & 1,11 & 1,34 & 1,00 & 0,67 & 1,36 & 1,00 \\
\hline & Escore Médio & & 3,57 & & & 3,59 & & & 3,58 \\
\hline & Escore Mediano & & 3,75 & & & 3,83 & & & 3,83 \\
\hline
\end{tabular}

Fonte: Elaboração própria.

Legenda: $\mathrm{CRQ}=$ comunidade remanescente de quilombo; $\mathrm{MD}=$ mediana; $\mathrm{DP}$ desvio padrão. 
$\mathrm{Na}$ Tabela 7 é possível observar que as relações pessoais são positivas em ambas as comunidades, e no geral (Md geral $=5,0)$ as pessoas consideram-se muito satisfeitos. Resultados semelhantes foram observados quanto à satisfação sexual ( $M d=4,0$, satisfeito). No que tange ao suporte social (apoio), as comunidades divergiram, pois na CRQ1, os entrevistados se declararam nem satisfeitos nem insatisfeitos, e na CRQ2, os moradores estavam muito satisfeitos (Md geral=4,0).

Em relação à "espiritualidade/religião/crenças pessoais", a maioria dos participantes de ambas as comunidades, embora afirmassem seguir a religião católica, relataram não frequentar ou participar ativamente. Poucos participam da religião de matriz africana (9,3 \% CRQ1 e 5,6\% CRQ2) e apenas 1,9\% na CRQ1 e 2,2\% na CRQ 2 afirmaram ser de religião católica e de matriz africana simultaneamente.

Ao avaliar o escore geral do domínio social $(4,33)$, é possível observar que se trata de um domínio com alta pontuação, o que significa que, em todas as facetas pesquisadas, os entrevistados estão satisfeitos com suas relações sociais e familiares.

Tabela 7 - Qualidade de vida, mediana e desvio padrão referentes ao domínio relações sociais das comunidades remanescentes de quilombo. Bahia, Brasil - 2018

\begin{tabular}{l|l|c|c|c|c|c|c|c|c}
\hline \multirow{2}{*}{ Questão } & \multirow{2}{*}{ Facetas } & \multicolumn{3}{c|}{ CRQ1 } & \multicolumn{3}{c|}{ CRQ2 } & \multicolumn{3}{c}{ Geral } \\
\cline { 3 - 10 } & & Média & MD & DP & Média & MD & DP & Média & MD \\
\hline 20 & Relações pessoais & 4,13 & 4,00 & 1,05 & 4,49 & 5,00 & 0,91 & 4,36 & 5,00 \\
21 & Suporte social & 3,19 & 3,50 & 1,60 & 4,09 & 5,00 & 1,19 & 3,75 & 4,00 \\
22 & Atividade sexual & 3,76 & 4,00 & 1,21 & 4,03 & 4,00 & 1,05 & 3,93 & 4,00 \\
& Escore Médio & & 3,69 & & & 4,21 & & & 4,01 \\
& Escore Mediano & & 3,83 & & & 4,67 & & & 4,33 \\
\hline
\end{tabular}

Fonte: Elaboração própria.

Legenda: $\mathrm{CRQ}=$ comunidade remanescente de quilombo; $\mathrm{MD}=$ mediana; $\mathrm{DP}=$ desvio padrão.

No domínio QV relacionado ao meio ambiente, diversas facetas apresentam escore bastante positivo (Md entre 4,0 e 5,0, como é o caso da "segurança física e proteção", "ambiente no lar", "cuidados de saúde e sociais", "participação e oportunidades de lazer" e "transporte". Esses escores refletem positivamente na QV dos cidadãos entrevistados. No que diz respeito ao acesso à saúde, que reflete positivamente na QV, a mediana geral foi de 4,0 (bom) (Tabela 8).

Entretanto, há insatisfação em ambas as comunidades relacionadas à distância entre a UBS e as comunidades. Verificou-se que a pior faceta em ambas as CRQ foi "recurso financeiro", que obteve a menor mediana entre os domínios estudados.

Tabela 8 - Qualidade de vida referente ao domínio meio ambiente das Comunidades Remanescentes de Quilombo. Bahia, Brasil - 2018

(continua)

\begin{tabular}{|c|c|c|c|c|c|c|c|c|c|c|}
\hline \multirow{2}{*}{ Questão } & \multirow{2}{*}{ Facetas } & \multicolumn{3}{|c|}{ CRQ1 } & \multicolumn{3}{|c|}{ CRQ2 } & \multicolumn{3}{|c|}{ Geral } \\
\hline & & Média & MD & DP & Média & MD & DP & Média & MD & DP \\
\hline 8 & $\begin{array}{l}\text { Segurança física e } \\
\text { proteção }\end{array}$ & 3,74 & 4,00 & 1,28 & 4,10 & 5,0 & 1,03 & 3,97 & 4,00 & 1,14 \\
\hline 9 & Ambiente no lar & 3,87 & 4,00 & 1,33 & 4,17 & 5,0 & 1,24 & 4,06 & 5,00 & 1,28 \\
\hline 12 & Recursos financeiros & 1,94 & 1,50 & 1,19 & 2,18 & 2,0 & 1,32 & 2,09 & 2,00 & 1,27 \\
\hline 13 & $\begin{array}{l}\text { Cuidados de saúde e } \\
\text { sociais: disponibilidade } \\
\text { e qualidade }\end{array}$ & 3,56 & 4,00 & 1,40 & 3,63 & 4,0 & 1,39 & 3,60 & 4,00 & 1,39 \\
\hline
\end{tabular}


Tabela 8 - Qualidade de vida referente ao domínio meio ambiente das Comunidades Remanescentes de Quilombo. Bahia, Brasil - 2018

(conclusão)

\begin{tabular}{|c|c|c|c|c|c|c|c|c|c|c|}
\hline \multirow{2}{*}{ Questão } & \multirow{2}{*}{ Facetas } & \multicolumn{3}{|c|}{ CRQ1 } & \multicolumn{3}{|c|}{ CRQ2 } & \multicolumn{3}{|c|}{ Geral } \\
\hline & & Média & MD & DP & Média & MD & DP & Média & MD & DP \\
\hline 14 & $\begin{array}{l}\text { Oportunidades } \\
\text { de adquirir novas } \\
\text { informações e } \\
\text { habilidades }\end{array}$ & 2,69 & 3,00 & 1,40 & 2,71 & 3,0 & 1,35 & 2,70 & 3,00 & 1,36 \\
\hline 23 & $\begin{array}{l}\text { Participação em, } \\
\text { oportunidades de } \\
\text { recreação/ lazer }\end{array}$ & 3,63 & 4,00 & 1,26 & 3,67 & 4,0 & 1,44 & 3,66 & 4,00 & 1,37 \\
\hline 24 & $\begin{array}{l}\text { Ambiente (físico, ruído, } \\
\text { trânsito, clima) }\end{array}$ & 2,76 & 3,00 & 1,48 & 2,92 & 3,0 & 1,49 & 2,86 & 3,00 & 1,49 \\
\hline \multirow[t]{3}{*}{25} & Transporte & 2,46 & 2,00 & 1,59 & 3,30 & 4,0 & 1,52 & 2,99 & 3,00 & 1,59 \\
\hline & Escore Médio & 3,08 & & & 3,34 & & & 3,24 & & \\
\hline & Escore Mediano & 3,19 & & & 3,75 & & & 3,50 & & \\
\hline
\end{tabular}

Fonte: Elaboração própria.

Legenda: $\mathrm{MD}=$ mediana; $\mathrm{DP}=$ desvio padrão.

\section{Discussão}

Nesta investigação, acredita-se que a faixa etária ligeiramente mais avançada dos moradores da CRQ2 pode estar relacionada ao fato de haver UBS que realiza atendimentos médicos e de enfermagem quinzenalmente. Outra questão é a ampla utilização da medicina alternativa, pois 84,3\% dos entrevistados afirmam utilizar ervas medicinais como forma de alívio de dores e desconfortos. A faixa etária predominantemente de jovens adultos entre 18 e 29 anos e do sexo feminino também foi observada por autores na Bahia e no Pará ${ }^{(7-9)}$.

Houve predominância da religião católica nas duas CRQ, embora haja moradores que seguem a matriz africana. A mescla entre as religiões católica e a de matriz africana, citada por alguns entrevistados na presente pesquisa, possui raiz histórica, pois os negros escondiam o seu culto aos orixás por medo de perseguição e assumiam, perante a sociedade, serem católicos. Dessa maneira, o culto aos orixás misturou-se ao culto dos santos católicos, forjando o sincretismo. Autores ${ }^{(10)}$ afirmam que as religiões de matriz africana (candomblé e umbanda), afro-ameríndia e o sincretismo religioso afrocatólico devem ser reconhecidos e valorizados, visando à consolidação e ao pleno exercício dos direitos culturais e religiosos de grupos e indivíduos afro-brasileiros, pautados em valores éticos e no convívio democrático em relação à cidadania multicultural.

Não obstante, a escolaridade também deve ser considerada, e embora se evidencie neste estudo baixo índice de pessoas analfabetas na CRQ2 (5,6\%), na CRQ1 o valor é maior (16,7\%). Segundo o Guia de políticas públicas para comunidades quilombolas, a porcentagem de quilombolas analfabetos no país é de $24,81 \%$, o que reflete o histórico de exclusão desses indivíduos nos espaços escolares, devido à falta de condições para sua permanência ou ausência de estabelecimentos de ensino no seu território ${ }^{(11)}$.

Em relação à QV Geral, os resultados desta pesquisa assemelham-se aos de outro estudo ${ }^{(4)}$, que analisou questões relativas aos aspectos gerais da QV e encontraram que, apesar de algumas pessoas possuírem comorbidades, a maioria avaliou sua QV e sua saúde de maneira positiva.

Em relação à QV referente ao Domínio Físico, pode-se observar que as dores e desconfortos corpóreos influenciaram diretamente nos resultados dos aspectos físicos. 
Estudo $^{(12)}$ relacionado a problemas crônicos de coluna ou dor nas costas (PCC/DC) foi realizado em quilombolas residentes em Guanambi (BA), que relatou que a prevalência desse agravo foi de 50,5\% dos indivíduos avaliados, maior que os 18,5\% encontrados na população brasileira. Para esses autores, os altos valores podem resultar da iniciação precoce dessa população em trabalhos que demandam elevado esforço físico desde a infância. Além disso, o PCC/DC pode acarretar na diminuição da capacidade física, do contato social, aumento de estresse e ansiedade, de problemas laborais e financeiros, além dos prejuízos relacionados ao custeio de tratamentos, auxílio-doença e aposentadoria por invalidez, gerando problemas pessoais, sociais e econômicos $^{(13)}$.

Em entrevista ${ }^{(14)}$ feita com os adultos na CRQ Barra do Aroeira, localizada no município de Santa Teresa (TO), foi constatado que o domínio físico apresentava o escore mais baixo tanto para homens como para as mulheres, visto que a influência maior no resultado desse escore foram as questões relacionadas a "dor e desconforto", "energia e fadiga" e "sono e repouso".

Embora a QV no Domínio Psicológico tenha obtido uma mediana geral boa, acredita-se ser imprescindível que os membros das comunidades realizem uma autorreflexão e releitura de sua própria identidade, pois as memórias têm valor e importância inestimáveis e devem ser valorizadas. Além disso, a busca por maneiras de ressaltar as experiências e raízes culturais das CRQ no Brasil é também uma forma de valorização da história cultural que não pode nem deve ser esquecida.

O baixo escore relacionado à faceta espiritualidade/religião/crenças pessoais gera preocupação, pois a falta de fé e esperança acarreta problemas físicos e mentais que reduzem a QV. Sobre o tema, autores ${ }^{(15)}$ relatam que as pessoas, de modo geral, procuram formas alternativas para o restabelecimento do bem-estar, e a busca pela religião é mencionada como uma alternativa para entender (fornecer sentido), orientar e controlar suas aflições cotidianas; enfim, há uma busca na religião por soluções para os mais variados problemas. Além disso, as pessoas que têm fé encontram uma oportunidade de participação social e de exercício de inclusão, muitas vezes negada em um mundo globalizado, individualista e competitivo.

Ainda no domínio psicológico, as facetas "pensar, aprender, memória e aparência"; "imagem corporal e aparência", "sentimentos negativos" também apresentaram mediana muito boa em outra pesquisa ${ }^{(16)}$, corroborando o presente estudo.

Bons resultados no Domínio Relações Sociais também foi encontrado em pesquisa nos municípios de Sapeaçú e Cruz das Almas (BA) que relata que a influência desse domínio na QV dos indivíduos pode estar relacionada com a segurança apresentada no domínio psicológico (sentimentos positivos, autoestima e boa imagem corporal $^{(16)}$.

Os laços familiares e de compadrio, bem como as redes culturais e religiosas, fazem com que haja pouca diferença entre os domínios de relações sociais e o psicológico ${ }^{(17)}$. Logo, os escores dos domínios sociais e psicológicos tendem a ser semelhantes, como encontrado no presente estudo.

Estudo ${ }^{(14)}$ percebeu que, na entrevista com os adultos, o domínio de relações sociais foi o que obteve o melhor escore, dando destaque à faceta "família", que obteve o maior resultado. Isso pode ser explicado pelo fato de haver nessa comunidade um predomínio de subsistência rural, que leva a um maior convívio familiar e maior valorização da família, como demonstram os escores mais elevados.

Um estudo sobre QV de idosos em 17 CRQ, no estado da Bahia, verificou que o domínio das relações sociais apresentou maior escore médio, seguido do domínio psicológico ${ }^{(18)}$. Estes resultados encontrados em vários estudos ${ }^{(14,16-18)}$ corroboram os resultados da presente pesquisa, referente aos melhores escores no domínio de relações sociais, seguido do domínio psicológico.

De modo geral, o domínio meio ambiente apresentou boa avaliação, embora autores ${ }^{(8)}$ destaquem que a cultura quilombola está se perdendo devido a inúmeros fatores, entre eles o 
desmatamento e a perda de recursos naturais em consequência das atividades agropecuárias que privilegiam as áreas de pastagens.

A pior faceta, em ambas as CRQ, foi "recurso financeiro", que obteve a menor mediana entre os domínios estudados. Esse comprometimento provavelmente seja decorrente de grande parte dos indivíduos entrevistados relatarem não possuir trabalho formal, embora $24,5 \%$ da população entrevistada possua ensino médio completo.

Diversos entrevistados na CRQ2 destacaram a importância do licuri como fonte de renda. Essa planta é fundamental na fabricação de diversos itens de artesanato: bolsas, chapéus, utensílios, abanos, esteiras, vassouras e outros objetos. Entretanto, há problemas no seu cultivo e vários moradores relataram que não há auxílio de agrônomo para orientar no plantio correto do licurizeiro.

É importante mencionar que esse auxílio está determinado no artigo 33 da Lei 12.288/2010 ${ }^{(19)}$, que estabelece que "Para fins de política agrícola, os remanescentes das comunidades dos quilombos receberão dos órgãos competentes tratamento especial diferenciado, assistência técnica e linhas especiais de financiamento público, destinados à realização de suas atividades produtivas e de infraestrutura”.

A condição renda per capita baixa está relacionada à autoavaliação negativa da saúde, sendo boa exemplificação quando se fala em fatores que promovem alterações negativas nos escores e na pior percepção de $\mathrm{QV}^{(14)}$.

Em estudo ${ }^{(18)}$ com idosos em 17 CRQ de Vitória da Conquista (BA), os resultados encontrados corroboram os acima citados, visto que a condição econômica é um fator social relevante que influencia diretamente a vida das famílias, que muitas vezes não podem contar com uma alimentação adequada, resultando em deficiência alimentar e baixa qualidade nutricional, o que pode impactar negativamente sua condição de saúde.

No que diz respeito ao acesso à saúde, que reflete positivamente na $\mathrm{QV}$, a mediana geral foi de 4,0 (bom). Entretanto, há relatos de insatisfação em ambas as comunidades, relacionados à distância entre a UBS e as comunidades.

Na CRQ1, os moradores se deslocam até um bairro da zona urbana para conseguirem atendimento. Esse fato resulta no não cumprimento da legislação n. 1.434/2004 ${ }^{(20)}$, que está relacionada à política de inclusão da população quilombola e determina a oferta de financiamento para a criação de UBS na própria comunidade visando assistir e atender de forma mais próxima às demandas das comunidades.

$\mathrm{Na}$ CRQ2, os atendimentos são quinzenais numa unidade de saúde satélite da comunidade, mas não funciona entre os meses de novembro e março. Além disso, no caso de vacinação, as mães devem se deslocar até o centro da cidade para vacinar seus filhos.

Os municípios precisam inserir adequadamente as comunidades quilombolas em seu planejamento político com vistas a melhorar as condições de oferta de esporte, lazer, transporte e saúde ${ }^{(21)}$.

Em relação à "participação em, e oportunidades de recreação/lazer" foi relatado que as principais atividades de lazer na CRQ1 são: fazer parte do grupo de coral da igreja, dançar no terreiro e cuidar da criação de animais domésticos (patos, galinhas, porcos...). Entretanto, um dado preocupante foi que $23 \%$ dos entrevistados relataram que o seu lazer está relacionado às idas ao bar, e 75,3\% dos entrevistados são consumidores frequentes de bebidas alcoólicas.

$\mathrm{Na}$ CRQ2, as atividades de lazer foram bastante diversificadas, destacando-se a prática de futebol, capoeira, diversas atividades na igreja, oficina de artesanato e teatro e rodas de samba; e apenas 37\% faz uso do álcool. Acredita-se que a existência de uma associação de moradores nessa comunidade seja determinante para a melhora desse quesito na QV desses indivíduos.

O consumo de bebidas alcoólicas também foi citado em estudo ${ }^{(22)}$ na CRQ do Kalunga (GO). O uso dessas bebidas representava, para os participantes, o "lado social da vida", sendo bastante utilizada em momentos festivos de confraternização. 
Estudo $^{(18)}$ identificou que o domínio ambiental obteve os menores escores médios entre os domínios de QV. Os piores aspectos ambientais mencionados estavam relacionados principalmente às condições dos locais de moradia, onde inexiste saneamento básico e tratamento da água, a higiene é inadequada, há deficiência na assistência à saúde e ausência de transporte.

Resultados semelhantes foram encontrados em cinco CRQ no Tocantins. O domínio meio ambiente obteve valores inferiores em todas as comunidades, o que pode estar relacionado à vulnerabilidade social da população estudada, resultando em precárias oportunidades de lazer e às dificuldades encontradas no ambiente físico ${ }^{(23)}$.

A principal limitação do estudo foi a dificuldade da coleta de dados em domicílio em uma das comunidades, pois, frequentemente, parte dos residentes estava realizando atividades laborais e o atendimento quinzenal na UBS, na outra comunidade, implicou no aumento do período da coleta.

\section{Conclusão}

Os resultados do estudo sugerem que os moradores das CRQ em estudo passam por dificuldades de acesso aos serviços e bens coletivos, sobretudo por condições sociais e econômicas ruins, decorrentes de uma história de injustiças e descaso com a população afrodescendente, que leva ao aumento da desigualdade social.

No domínio físico há baixo escore nas variáveis dor e desconforto, assim como queixa de falta de energia para as atividades diárias e fadiga. Portanto, para amenizar esses problemas na população amostrada neste estudo, e que impactam negativamente a condição de saúde dos indivíduos, é necessária a implantação nas UBS de um atendimento holístico, cujo objetivo não seja apenas amenizar dores e desconforto, e sim, promover a melhora da QV.

A única variável, em ambas as comunidades, que obteve um baixo escore no domínio psicológico foi a espiritualidade. E com relação ao domínio meio ambiente, a variável recurso financeiro obteve os escores mais baixos nas duas comunidades, e o domínio relações sociais houve resultados satisfatórios.

Fazendo uma análise geral dos escores das facetas obtidos na pesquisa, conclui-se que as CRQ possuem perfis semelhantes quanto aos aspectos de qualidade de vida. Entretanto, quando se faz uma observação mais detalhada, pode-se perceber que o resultado encontrado em algumas variáveis na comunidade do CRQ2 foi melhor que o encontrado na CRQ1. Este fato pode estar atrelado à união entre as pessoas da CRQ2, visto que há uma associação comunitária bastante participativa na vida e lazer dos moradores. Outro fator que pode refletir positivamente é a existência de uma UBS satélite na CRQ2, que facilita o acesso da comunidade aos serviços de assistência à saúde.

Diante do exposto, é imprescindível a efetivação das políticas sociais existentes, principalmente relacionadas à saúde, adaptando a dinâmica de trabalho dos programas de saúde para a realidade quilombola. A luta das comunidades quilombolas persiste, e visa à busca por reconhecimento étnico-cultural e histórico, preservação da espiritualidade, religião e crenças pessoais.

\section{Colaborações:}

1 - Concepção, projeto, análise e interpretação dos dados: Milleidy Cezar Peixoto;

2 - Redação do artigo e revisão crítica relevante do conteúdo intelectual: Cláudia Cecília Blaszkowski de Jacobi e Larissa Rolim Borges-Paluch;

3 - aprovação final da versão a ser publicada: Cláudia Cecília Blaszkowski de Jacobi e Larissa Rolim Borges-Paluch.

\section{Referências}

1. Silva LFS, Simionatto I. Quilombolas no contexto de luta pela terra. In: Seminário Internacional Fazendo Gênero - Diásporas, Diversidades, Deslocamentos, 9, 2010, Florianópolis (SC). Anais (on-line) Santa Catarina: Universidade Federal de Santa Catarina; 2010 [cited 2017 May 14]. Available from: http://www.fazendogenero.ufsc. br/9/resources/anais/1278295675_ARQUIVO_ ArtigoFazendoGenero9-VersaoFinal.pdf 
2. Costa ES, Scarcelli IR. Psicologia, política pública para a população quilombola e racismo. Psicologia USP. 2016;27(2):357-66. DOI: http://dx.doi.org/10. $1590 / 0103-656420130051$

3. Silva CBR, Ferreira CGS, Rodrigues FL. Saúde quilombola no Maranhão. Ambivalências. 2016;4(7):106-33. DOI: https://doi.org/10.21665/ 2318-3888.v4n7p106-133

4. Roberti MRF, Moreira CLNSO, Tavares RS, Borges Filho HM, Silva AG, Maia CHG, et al. Avaliação da qualidade de vida em portadores de doença falciforme do Hospital das Clínicas de Goiás, Brasil. Rev Bras Hematol Hemoter. 2010:32(6):449-54. DOI: https://doi.org/10.1590/ S1516-84842010000600008

5. Brasil. Ministério da Saúde. Conselho Nacional de Saúde. Resolução no 466, de 12 de dezembro de 2012. Aprova as diretrizes e normas regulamentadoras de pesquisas envolvendo seres humanos [Internet]. Brasília (DF); 2012 [cited 2014 Nov 20]. Available from: http://conselho.saude. gov.br/resolucoes/2012/Reso466.pdf

6. Conselho Federal de Enfermagem. Resolução 580/2018, de 6 de julho de 2018. Atualiza o Manual de Procedimentos Administrativos para registro e inscrição de profissionais. Identificação obrigatória de gêneros masculino e feminino [Internet]. Brasília (DF); 2018 [cited 2018 Nov 12]. Available from: http://www.cofen.gov.br/ resolucao-cofen-no-580-2018_64035.html

7. Gomes KO, Reis EA, Guimarães MDC, Cherchiglia ML. Utilização de serviços de saúde por população quilombola do Sudoeste da Bahia, Brasil. Cad Saúde Pública. 2013;29(9):1829-42. DOI: https://doi.org/10.1590/0102-311X00151412

8. Freitas IA, Rodrigues ILA, Silva IFS, Nogueira LMV. Perfil sociodemográfico e epidemiológico de uma comunidade quilombola na Amazônia Brasileira. Rev Cuid. 2018;9(2):2187-200. DOI: https://doi. org/10.15649/cuidarte.v9i2.521

9. Bezerra VM, Andrade ACS, César CC, Caiaffa WT. Comunidades quilombolas de Vitória da Conquista, Bahia, Brasil: hipertensão arterial e fatores associados. Cad Saúde Pública. 2013;29(9):1889-902. DOI: https://doi.org/10.1590/0102-311X00164912

10. Pelosi SM, Pomari LR. Valorização da religião afro-brasileira: diversidade, respeito e cidadania [Internet]. Cadernos PDE. 2014 [cited 2019 May 13];1. Available from: http://www.diaadiaeducacao.pr. gov.br/portals/cadernospde/pdebusca/producoes_ pde/2014/2014_unespar-paranavai_hist_artigo_ sonia_maria_pelosi.pdf

11. Secretaria de Políticas de Promoção da Igualdade Racial. Secretaria de Políticas para Comunidades Tradicionais. Guia de políticas públicas para comunidades quilombolas [Internet]. Brasília; 2013 [cited 2018 Nov 19]. Available from: https: //www.gov.br/mdh/pt-br/centrais-de-conteudo/ igualdade-racial/guia-de-politicas-publicas-paracomunidades-quilombolas/view

12. Teixeira EP, Mussi RFF, Petroski EL, Munaro HLR, Figueiredo ACMG. Problema crônico de coluna/ dor nas costas em população quilombolas de região baiana, nordeste brasileiro. Fisioter Pesqui. 2019;26(1):85-90. DOI: http://dx.doi.org/ 10.1590/1809-2950/18024126012019

13. Malta DC, Oliveira MM, Andrade SSCA, Caiaffa WT, Souza MFM, Bernal RTI. Fatores associados à dor crônica na coluna em adultos no Brasil. Rev Saúde Pública. 2017;51(Suppl 1):9s. DOI: https://10.1590/ S1518-8787.2017051000052

14. Sousa LVA, Maciel ES, Quaresma FRP, Paiva LS, Fonseca FLA, Adami F. Descrição da percepção da qualidade de vida de moradores de um quilombo no norte do Brasil. J Hum Growth Dev. 2018;28(2):199-205.DOI:https://dx.doi.org/10.7322/ jhgd.147239

15. Cerqueira-Santos E, Koller SH, Pereira MTLN. Religião, saúde e cura: um estudo entre neopentecostais. Psicol cienc prof. 2004;24(3):82-91. DOI: https://doi.org/10.1590/ S1414-98932004000300011

16. Silva LS. Vulnerabilidades na qualidade de vida de pessoas com doença falciforme em municípios do recôncavo baiano [dissertação]. Governador Mangabeira (BA): Faculdade Maria Milza; 2016.

17. Velten APC, Moraes AN, Oliveira ERA, Melchiors AC, Secchin CMC, Lima EFA. Qualidade de vida e hipertensão em comunidades quilombolas do norte do Espírito Santo, Brasil. Rev Bras Pesq Saúde [Internet]. 2013 [cited 2018 Jul 8];15(1):9-16. Available from: https://www.researchgate.net/publication/ 327947095_Qualidade_de_vida_e_hipertensao_em_ comunidades_quilombolas_do_norte_do_Espirito_ Santo_Brasil

18. Santos VC, Boery EN, Pereira R, Santa Rosa DO, Vilela ABA, Anjos KF, et al. Socioeconomic and health conditions associated with quality of life of elderly quilombolas. Texto contexto 
- enferm. 2016;25(2):e1300015. DOI: http://dx.doi. org/10.1590/0104-07072016001300015

19. Brasil. Presidência da República. Lei $\mathrm{n}^{\circ}$ 12.288, de 20 de julho de 2010. Institui o Estatuto da Igualdade Racial [Internet]. Brasília (DF); 2010 [cited 2018 Oct 20]. Available from: http://www. planalto.gov.br/ccivil_03/_ato2007-2010/2010/lei/ 112288.htm

20. Brasil. Ministério da Saúde. Portaria no 1.434 , de 14 de julho de 2004. Define mudanças no financiamento da atenção básica em saúde no âmbito da estratégia Saúde da Família, e dá outras providências [Internet]. Brasília (DF); 2004 [cited 2017 Jul 24]. Available from: http://www1.saude. rs.gov.br/dados/11652498269352\%20Portaria $\% 20$ n\%BA\%201434\%20de\%2014\%20de\%20julho\%20 de\%202004.pdf

21. Rangel R, Miranda ACM, Lara LM. Política pública de esporte e lazer no feixo: experiências de pesquisa em uma comunidade quilombola no Paraná. Licere [Internet]. 2014 [cited 2018 Sep 20];17(1):1-31. Available from: file://C:/ Users/05023/Downloads/627-Texto\%20do\%20 artigo-3116-1-10-20140605\%20(1).pdf

22. Novais TO. O uso de álcool e outras drogas na comunidade rural quilombola Kalunga em Goiás. Comun ciênc saúde [Internet]. 2017 [cited 2018 Set 06]:28(3-4):379-88. Available from: http://www.escs.edu.br/revistaccs/index.php/ comunicacaoemcienciasdasaude/article/view/280

23. Sousa LVA, Maciel ES, Quaresma FRP, Abreu ACG, Paiva LS, Fonseca FLA, et al. Qualidade de vida e Síndrome Metabólica em comunidades Quilombolas brasileiras: Estudo Transversal. J Hum Growth Dev. 2018;28(3):316-28. DOI: https://doi.org/10.7322/jhgd.152182

Recebido: 13 de novembro de 2019 Aprovado: 9 de maio de 2020 Publicado: 29 de junho de 2020

A Revista Baiana de Enfermagem utiliza a Licença Creative Commons - Atribuição-NãoComercial 4.0 Internacional. https://creativecommons.org/licenses/by-nc/4.0/ Este artigo é de acesso aberto distribuído sob os termos da Licença Creative Commons (CC BY-NC). Esta licença permite que outros remixem, adaptem e criem a partir do seu trabalho para fins não comerciais. Embora os novos trabalhos tenham de lhe atribuir o devido crédito e não possam ser usados para fins comerciais, os usuários não têm de licenciar esses trabalhos derivados sob os mesmos termos. 